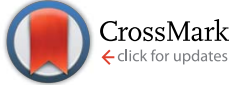

Cite this: RSC Adv., 2017, 7, 16078

Received 23rd November 2016 Accepted 28th February 2017

DOI: 10.1039/c6ra27199e

rsc.li/rsc-advances

\section{Formation mechanism and properties of fluoride- phosphate conversion coating on titanium alloy}

\author{
Shuaixing Wang, ${ }^{\text {a }}$ Xiaohui Liu, ${ }^{\mathrm{a}}$ Liqiang Wang, ${ }^{\mathrm{b}}$ Qingjie Wen, ${ }^{\mathrm{b}}$ Nan Du ${ }^{\mathrm{a}}$ \\ and Jianhang Huang ${ }^{a}$
}

A uniform grey conversion coating with the thickness of 4-5 $\mu \mathrm{m}$ was prepared on titanium alloy by a fluoride-phosphate treatment. Scratch testing results indicated that the conversion coating greatly improved the adhesion strength of the paint coat to the titanium substrate. The growth mechanism of the conversion coating was analyzed comprehensively by $E-t$ curve, SEM, EDS, XPS and XRD. In the conversion process, the titanium substrate was first dissolved $(0-45 \mathrm{~s})$, then $\mathrm{Na}_{3} \mathrm{TiF}_{6}$ nucleation occurred via a series of reactions (45-120 s), whereby the conversion coating grew steadily with the nucleation and growth of $\mathrm{Na}_{3} \mathrm{TiF}_{6}$ grains (120-600 s); after $600 \mathrm{~s}$, the conversion coating reached dynamic equilibrium of growth/dissolution. In the drying process at $100 \pm 5{ }^{\circ} \mathrm{C}$, some $\mathrm{Na}_{3} \mathrm{TiF}_{6}$ grains reacted with $\mathrm{O}_{2}$ to form $\mathrm{Na}_{3} \mathrm{TiOF}_{5}$. The components of the conversion coating were $\mathrm{Na}_{3} \mathrm{TiF}_{6}, \mathrm{Na}_{3} \mathrm{TiOF}_{5}$, a little $\mathrm{TiO}_{2}$, $\mathrm{TiF}_{4}$ and phosphate derivatives.

\section{Introduction}

Titanium and its alloys are increasingly applied in the aerospace industry, such as in airframes, engine components, fasteners and others, owing to their excellent combination of low density, high strength-to-weight ratio and good corrosion resistance. ${ }^{\mathbf{1 , 2}}$ However, drawbacks, such as low surface hardness, high friction coefficient and poor adhesion with organic coatings, limit the direct application of titanium alloys. A variety of surface treatment technologies, including anodizing, micro-arc oxidation, chemical conversion, surface alloying and physical vapour deposition, have been employed to improve the surface performance of titanium alloys. ${ }^{3}$ Amongst the mentioned surface treatment technologies, chemical conversion coating is the primary surface pretreatment for titanium alloy in the aerospace industry, and it provides good corrosion protection, promotes the adhesion with paints and has a low processing cost., However, an excellent coating is difficult to convert on titanium using the traditional chemical conversion technology based on chromates and phosphates, ${ }^{6-8}$ due to the presence of the passive oxide film. Therefore, zinc phosphating, ${ }^{9}$ trivalent chromiumphosphated conversion ${ }^{\mathbf{1 0 , 1 1}}$ and fluoride-phosphate conversion coating $^{12}$ are gradually being developed in line with the existing and emerging requirements. Besides, the eco-friendly pretreatment techniques for aluminium alloy, including rare-earth conversion, ${ }^{\mathbf{1 3 , 1 4}}$ molybdate conversion, ${ }^{15}$ silane treatment, ${ }^{\mathbf{1 6}}$

${ }^{a}$ National Defense Key Discipline Laboratory of Light Alloy Processing Science and Technology, Nanchang Hangkong University, Nanchang 330063, P. R. China. E-mail: wsxxpg@126.com

${ }^{b}$ AVIC Chengdu Aircraft Industrial (Group) Co., Ltd., Chengdu 610091, P. R. China phytic acid (PA) treatment ${ }^{17}$ and $\mathrm{Zr} / \mathrm{Ti}$-based treatment ${ }^{18-20}$ may also be used for the pretreatment of titanium alloy. In general, the fluoride-phosphate conversion technique is the most effective pretreatment system for titanium alloy, and has even been adopted as an official aerospace material specification (AMS 2486D). ${ }^{12}$ However, so far there has been no report about the chemical composition, microstructure and formation mechanism of the fluoride-phosphate conversion coating on titanium alloy.

In many case, the precipitation of these ultra-thin conversion coatings is an electrochemically driven process and requires the dissolution of alloy and a subsequent film deposition.,17,20-24 The literature ${ }^{\mathbf{2 0 , 2 1}}$ reports that the formation of a Ti/Zr-based conversion coating on aluminium alloy can be deemed as a nucleation, followed by the growth of $\mathrm{Na}_{3} \mathrm{AlF}_{6}$ crystal and formation of a metal-organic complex. In the formation process of a zinc phosphate (ZPO) layer on aluminium, ZPO crystals primarily occur on and around the intermetallic particles. ${ }^{22}$ $\mathrm{ZhaO}^{9}$ indicated that ZPO conversion coating on pure titanium experiences a similar nucleation step, and that ultrasonic irradiation can improve the nucleation and growth of ZPO. Besides, $\mathrm{Li}^{17}$ found that PA induced the effective deposition of reaction products and the formation of the conversion coating in a mixed conversion system of $\mathrm{PA}$ and $\mathrm{NH}_{4} \mathrm{~F}$ for Ti-6Al-4V alloy. Although the formation of a fluoride-phosphate conversion coating on titanium alloy may undergo similar processes, the basic theories about the coating composition and the coatingforming reactions are not yet clear, until now.

The aim of the present work was to gain an insight into the deposition mechanism of a fluoride-phosphate conversion coating on titanium alloy. For this purpose, the open circuit 
potential (OCP) of titanium alloy in a conversion bath was completely monitored. The transformation of the morphology and the chemical composition of the coating during the conversion process were analyzed by SEM and EDS. In addition, X-ray photoelectron spectroscopy (XPS) and X-ray diffraction (XRD) were used to accurately determine the chemical composition of the conversion coating. Moreover, the corrosion resistance and the paint adhesion of the conversion coating were evaluated by electrochemical impedance spectroscopy (EIS) and scratch testing, respectively. A possible formation mechanism for a fluoride-phosphate conversion coating on TC1 alloy is proposed.

\section{Experimental}

\subsection{Materials}

TC1 panels of $2.0 \mathrm{~mm}$ thickness were supplied by Baoti Corp., China. The main chemical composition of the TC1 alloy was 1.0-2.5 wt $\%$ Al, $0.7-2.0 \mathrm{wt} \% \mathrm{Mn}, 0.30 \mathrm{wt} \% \mathrm{Si}$, and bal. Al. The specimens with a dimension of $25 \mathrm{~mm} \times 20 \mathrm{~mm}$ were cut from the panels, polished with abrasive papers, ultrasonically cleaned in ethanol and finally dried in warm air.

\subsection{Preparation of conversion coating}

Prior to chemical conversion treatment, the samples were sequentially treated by the following steps: degreasing in an aqueous solution containing $30 \mathrm{~g} \mathrm{~L}^{-1} \mathrm{Na}_{2} \mathrm{CO}_{3}, 20 \mathrm{~g} \mathrm{~L}^{-1} \mathrm{Na}_{3} \mathrm{PO}_{4}$ and $5 \mathrm{~g} \mathrm{~L}^{-1} \mathrm{Na}_{2} \mathrm{SiO}_{3}$ at $60{ }^{\circ} \mathrm{C}$ for $2 \mathrm{~min}$, rinsing in deionised water, pickling in $20 \mathrm{vol} \% \mathrm{HNO}_{3}$ solution at room temperature for $1 \mathrm{~min}$ and finally rinsing with deionised water.

The cleaned samples were immediately immersed in a fluoride-phosphate conversion solution at $30 \pm 3{ }^{\circ} \mathrm{C}$ for different times. The conversion bath consisted of $40 \mathrm{~g} \mathrm{~L}^{-1} \mathrm{Na}_{3} \mathrm{PO}_{4}, 15 \mathrm{~g}$ $\mathrm{L}^{-1} \mathrm{NaF}$ and $25 \mathrm{~mL} \mathrm{~L}^{-1} \mathrm{HAc}$. The $\mathrm{pH}$ of the conversion baths was adjusted to $4.0-5.0$ by adding $\mathrm{HF}$ or $\mathrm{NaOH}$ solution. After the surface treatment, the samples were rinsed thoroughly with deionised water, and then dried in warm air or at $100 \pm 5{ }^{\circ} \mathrm{C}$ for $30 \mathrm{~min}$.

\subsection{Electrochemical tests}

Electrochemical tests were conducted by using an Autolab PGSTAT $302 \mathrm{~N}$. The tests were performed by using a threeelectrode electrochemical cell. A saturated calomel electrode (SCE) and a platinum sheet were used as the reference and counter electrodes, respectively. The titanium specimens were coated with epoxy resin, with an area of $1 \mathrm{~cm}^{2}$ left exposed for the electrochemical testing. $E-t$ curves of the TC1 samples in the conversion bath were acquired for $20 \mathrm{~min}$, with a step of $1 \mathrm{~s}$. EIS values of the samples in $3.5 \mathrm{wt} \% \mathrm{NaCl}$ solution were acquired at the OCP over the frequency range of $10^{5}$ to $10^{-2} \mathrm{~Hz}$ using an AC signal amplitude of $10 \mathrm{mV}$. Prior to testing, the samples were immersed for $\sim 0.5 \mathrm{~h}$ in a $\mathrm{NaCl}$ solution in order to stabilize the OCP. The equivalent circuits were fitted using the Zsimpwin software. All the experiments were repeated with three duplicate specimens to confirm the reproducibility of the results, and the typical result or the average of the three measurements is reported in this paper.

\subsection{Characterization}

The surface morphology and cross-sectional morphology of the conversion coating were analyzed by field emission gun SEM (FE-SEM, Nova Nano-SEM 450). Cross-sections of the specimens were ground by successive grades of SiC paper, followed by finishing with a $1 \mu \mathrm{m}$ diamond. The chemical compositions were examined by energy dispersive X-ray spectroscopy (EDS, INCA 250). Phase compositions were investigated by X-ray diffraction analysis (XRD) using a Bruker D8 ADVANCE instrument equipped with $\mathrm{Cu} \mathrm{K} \alpha$. The intensity data were collected in a $2 \theta$ range from $10^{\circ}$ to $70^{\circ}$ with a scan rate of $0.02^{\circ} \mathrm{s}^{-1}$. X-ray photoelectron spectroscopy (XPS) measurements were conducted in an Axis Ultra DLD equipped with a standard $\mathrm{Al} \mathrm{K} \alpha \mathrm{X}$ ray source $(1486.6 \mathrm{eV})$ and a hemispherical analyzer.

\subsection{Paint adhesion}

TC1 samples without and with chemical treatments were painted with S06-1010H polyurethane primer (Tianjin Lighthouse Coating Co., Ltd., China). The thickness of the paint coat was about $30-35 \mu \mathrm{m}$. The adhesion of the polyurethane coating to the substrates was determined by a single scratch tester (WS2005, Lanzhou Institute of Chemical Physics, CAS, China). The measurements were done before (dry adhesion) and after (wet adhesion) 7 days of the paint-coated samples exposure to $3.5 \mathrm{wt} \% \mathrm{NaCl}$ solution. During the scratch testing, acoustic emission (AE) signals were measured with a diamond indenter $\left(120^{\circ}\right.$ cone with a $200 \mu \mathrm{m}$ radius tip) under a loading rate of $40 \mathrm{~N}$ min $^{-1}$, loading range of $0-80 \mathrm{~N}$ and scratch length of $6 \mathrm{~mm}$. During the scratch testing, the load at which the coating was removed from the substrate was designated as the critical load $\left(L_{\mathrm{C}}\right)$ and the moment was recorded by an acoustic emission (AE) signal. ${ }^{25}$ The profiles of the scratched coating were measured using a KH-7700 3D video microscope.

\section{Results and discussion}

\subsection{Coating growth curve}

Fig. 1 shows the variation curves of the OCP and the coating weight in the fluoride-phosphate conversion process. It was found that the OCP decreased sharply before $45 \mathrm{~s}$, and then greatly increased at 45-600 s and then became stabile after $600 \mathrm{~s}$. The coating weight had a similar variation law with the OCP at 120-900 s. The coating weight increased sharply at 120$420 \mathrm{~s}$, increased slightly at $420-600 \mathrm{~s}$, but tended to be stable at 600-900 s. According to the variation of the OCP and coating weight, the growth process for the conversion coating can be divided into four stages: dissolution of the substrate $(0-45 \mathrm{~s})$, rapid growth of the coating (45-420 s), slow growth of the coating (420-600 s) and the dynamic equilibrium of the coating growth/dissolution (>600 s).

The fluoride-phosphate conversion bath was made mildly acidic by adjusting the $\mathrm{pH}$ in the range of 4.0-5.0. When the sample was immersed in the conversion bath, the titanium 


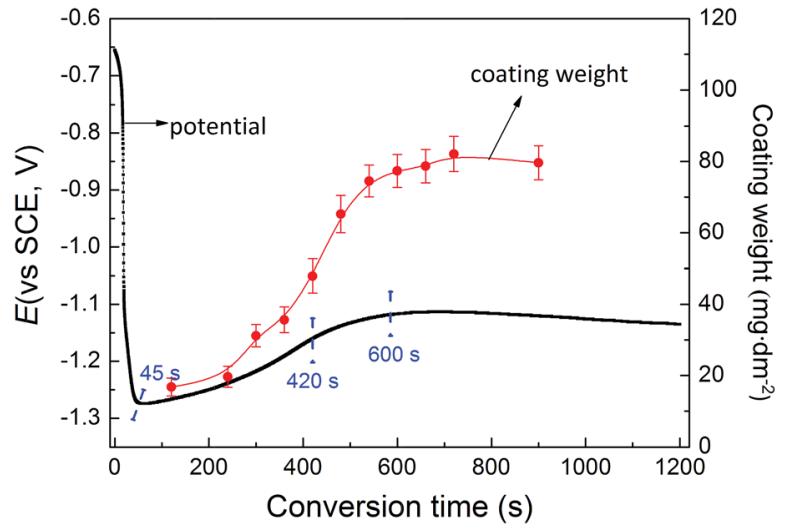

Fig. $1 E-t$ curve in the conversion process and growth curve of the fluoride-phosphate conversion coating.

substrate was immediately dissolved to $\mathrm{Ti}^{4+}$. In this stage (0-45 $\mathrm{s})$, the OCP decreased sharply, accompanied with hydrogen evolution. With the increasing of $\mathrm{Ti}^{4+}$ on the interface of the electrode/solution, nucleation was formed on the partial sites of the bare substrate via stepwise reactions, at which point, the grains continuously nucleated and grew to form the primary conversion coating. Therefore, the coating grew rapidly, and the OCP increased greatly at $45-420 \mathrm{~s}$. With the thickening of the coating, the dissolution of the titanium substrate and the diffusion of $\mathrm{Ti}^{4+}$ became difficult, and the growth of grains became inhibited. However, a little $\mathrm{Ti}^{4+}$ could be still formed from micro-dissolution of the conversion bath on the primary coating, and so the nucleation reactions still occurred at the coating/solution interface. So the conversion coating still grew slowly in this stage (420-600 s). Meanwhile, the OCP increased slightly. After $600 \mathrm{~s}$, the dissolving of the coating was aggravated, and the conversion process entered the dynamic stage of coating growth/dissolution, and thus the coating did not grow and the OCP stabilized.

\subsection{Coating morphologies}

Fig. 2a-e give the surface morphologies of the fluoride-phosphate conversion coating formed at different times. As shown in Fig. 2a, grains formed on the partial sites of the TC1 surface when the sample was immersed in the conversion bath for $2 \mathrm{~min}$, but most regions were in the activated state. As the conversion time was extended, the nucleation sites increased and the grains gradually grew. There were many larger grains on the electrode surface at $4 \mathrm{~min}$, as shown in Fig. 2b. When the conversion time was $6 \mathrm{~min}$, the grains nearly covered all of the surface to form the primary conversion coating. Besides this, the nucleation reaction can also occur at the interface of the coating/solution, and secondary grains could be formed on the coating surface, as shown in Fig. 2c. A complete and uniform conversion coating could be found after $10 \mathrm{~min}$ (Fig. 2d and e). Meanwhile, the secondary grains appeared on the surface with the complete coating.

Fig. 2f shows the cross-sectional morphology and elemental distribution of the fluoride-phosphate conversion coating formed at 10 min. As shown in Fig. 2f, the conversion coating was about $4-5 \mu \mathrm{m}$ thickness, uniform and it closely adhered to
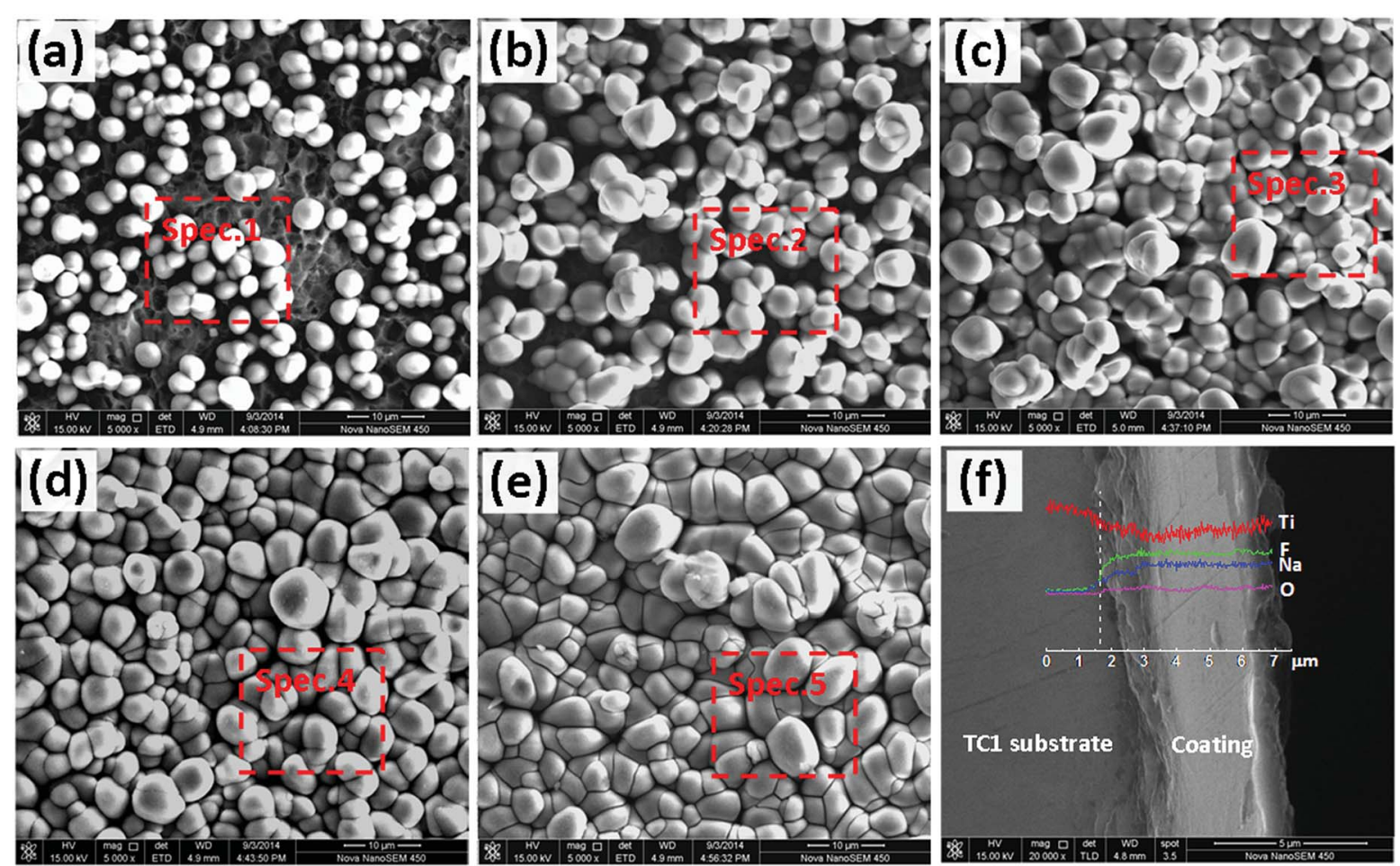

Fig. 2 Surface SEM images of the fluoride-phosphate conversion coating formed at: 2 min (a), 4 min (b), 6 min (c), 10 min (d) and 15 min (e). Cross-section SEM image and EDS spectrum of the conversion coating formed at 10 min (f). 
Table 1 Elemental composition and the contents of the different conversion coatings marked in Fig. 2

\begin{tabular}{llllllll}
\hline & & \multicolumn{7}{c}{ Elements (wt\%) } \\
\cline { 3 - 8 } Coating & Location & $\mathrm{Ti}$ & $\mathrm{O}$ & $\mathrm{F}$ & $\mathrm{Na}$ & $\mathrm{P}$ & $\mathrm{Al}$ \\
\hline $2 \mathrm{~min}$ & Spec.1 & 35.66 & 5.91 & 44.63 & 12.29 & 0.53 & 0.37 \\
$4 \mathrm{~min}$ & Spec.2 & 24.18 & 5.77 & 51.54 & 17.43 & 0.75 & - \\
$6 \mathrm{~min}$ & Spec.3 & 21.67 & 5.89 & 52.62 & 18.97 & 0.85 & - \\
$10 \mathrm{~min}$ & Spec.4 & 16.54 & 5.22 & 54.83 & 22.34 & 1.07 & - \\
$15 \mathrm{~min}$ & Spec.5 & 17.00 & 5.64 & 54.12 & 22.11 & 1.13 & - \\
& & & & & & &
\end{tabular}

the substrate, suggesting a high interface bonding strength. Besides, the conversion coating exhibited a tendency of outgrowth. From the coating/substrate interface to the coating surface, Ti element showed a decreasing trend, while $\mathrm{F}$ and $\mathrm{Na}$ elements increased gradually to a stable content within $\sim 3 \mu \mathrm{m}$ of the substrate.

\subsection{Coating composition}

Table 1 gives the element information of the different conversion coatings marked in Fig. 2. As shown in Table 1, all the coatings had Ti, F, Na, O and a little P. Besides, while the Ti content decreased, the $\mathrm{F}$ and $\mathrm{Na}$ contents ascended and the $\mathrm{O}$ content was maintained at about $5 \mathrm{wt} \%$ with the increase in conversion time. It could be confirmed that Ti mainly came from the TC1 substrate. The high levels of F and Na suggested the conversion bath was involved in the coating-forming reactions. Moreover, the changes of Ti, F and Na could illustrate the growth process of the coating. As the conversion time increased, the coating thickened and $\mathrm{Ti}^{4+}$ formed by dissolution of the substrate could not be effectively diffused into the coating surface, but the coating-forming reactions still occurred, relying on there being a little $\mathrm{Ti}^{4+}$ formed by the microdissolution of the primary coating, which resulted in

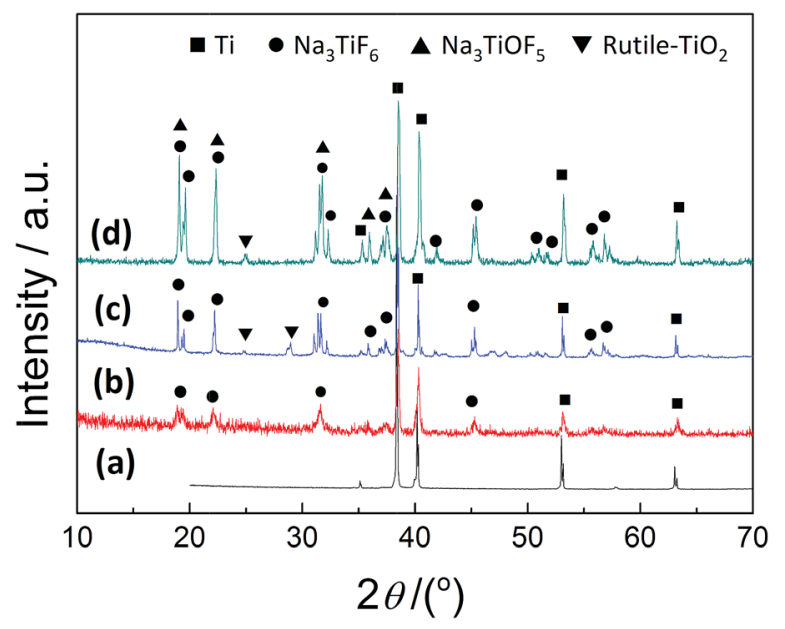

Fig. 3 XRD patterns of bare TC1 alloy (a) and fluoride-phosphate conversion coatings formed at: $4 \mathrm{~min}$ (b), $10 \mathrm{~min}$ (c) and coating with drying at $100{ }^{\circ} \mathrm{C}$ for $30 \mathrm{~min}$ (d). a decrease in the Ti content and an increase in the $\mathrm{F}$ and $\mathrm{Na}$ contents. Interestingly, the variation of $\mathrm{F}$ and $\mathrm{Na}$ in Table 2 is consistent with the variation in Fig. 2 f. Both Table 2 and Fig. $2 \mathrm{f}$ confirmed that the growth of the conversion coating mainly depended on the reaction of the conversion bath with $\mathrm{Ti}^{4+}$ formed by dissolution of the primary coating in the later stage of film-forming.

XRD patterns of the bare TC1 alloy and various fluoridephosphate conversion coatings are illustrated in Fig. 3. It can be seen that there were obvious differences in the XRD patterns between bare and coated TC1 alloy. For the bare TC1 alloy (Fig. 3a), only Ti peaks were characterized, since the self-formed oxide film was too thin to be reflected by XRD. The peaks of $\mathrm{Na}_{3} \mathrm{TiF}_{6}$ were detected in the conversion coating just formed after $4 \mathrm{~min}$. With the extension in the film-forming time, numerous $\mathrm{Na}_{3} \mathrm{TiF}_{6}$ and a few rutile- $\mathrm{TiO}_{2}$ were present in the coating formed at $10 \mathrm{~min}$ (Fig. 3c). Besides, as shown in Fig. 3d, many strong diffraction peaks attributed to $\mathrm{Na}_{3} \mathrm{TiOF}_{5}$ were also identified in the coating after drying at $100{ }^{\circ} \mathrm{C}$ for $30 \mathrm{~min}$. This phenomenon indicated that some $\mathrm{Na}_{3} \mathrm{TiF}_{6}$ may react with $\mathrm{O}_{2}$ to form $\mathrm{Na}_{3} \mathrm{TiOF}_{5}$ in the drying process. ${ }^{26}$

Moreover, Fig. 4 a presents the XPS survey spectra of the bare TC1 alloy and the fluoride-phosphate conversion coating formed at $10 \mathrm{~min}$. The details of the peaks of Ti 2p, O 1s, F 1s, $\mathrm{Na} 1 \mathrm{~s}$ and P 2p are shown in Fig. 4b-f, respectively. The survey spectra (Fig. 4a) indicate the presence of Ti, O and Al at the TC1 surface. According to the binding energy of Ti $2 \mathrm{p}$ and $\mathrm{O} 1 \mathrm{~s}$, it can be determined that both pure- $\mathrm{Ti}, \mathrm{TiO}_{2}$ and a few $\mathrm{Al}_{2} \mathrm{O}_{3}$ exist on the surface of the TC1 alloy.

However, Ti, F, O, Na and $\mathrm{P}$ were detected on the coating surface, which is basically consistent with the EDS results. As shown in Fig. $4 \mathrm{~b}$, the Ti $2 \mathrm{p}_{3 / 2}$ core-level spectrum could be curve-fitted into two peak with binding energies at about $459.2 \mathrm{eV}$ and $460.1 \mathrm{eV}$, which were assigned to $\mathrm{TiO}_{2}$ (ref. 27) and fluorinated titanium, ${ }^{27,28}$ respectively. The $\mathrm{O} 1 \mathrm{~s}$ spectrum (Fig. 4c) consists of three peaks. The main peak at $531.5 \mathrm{eV}$ might be associated with oxygen bound to multiple fluorine atoms (O-F).$^{29}$ The other peaks at $530.1 \mathrm{eV}$ and $533.3 \mathrm{eV}$ were attributed to $\mathrm{TiO}_{2}$ and $\mathrm{O}=\mathrm{P}-$, respectively. The binding energy of $\mathrm{F} 1 \mathrm{~s}$ (Fig. 4d) was about $685.1 \mathrm{eV}$, which represented $\mathrm{TiF}_{4}$ or $\mathrm{Na}_{3} \mathrm{TiF}_{6}{ }^{2{ }^{2-30}}$ The only peak of $\mathrm{Na} 1 \mathrm{~s}$ (Fig. 4e) at $1071.6 \mathrm{eV}$ also corresponded to $\mathrm{Na}_{3} \mathrm{TiF}_{6}$. Besides, the $\mathrm{O} 1 \mathrm{~s}$ peak at $533.3 \mathrm{eV}$ and the $\mathrm{P} 2 \mathrm{p}$ peaks (Fig. $4 \mathrm{f}$ ) showed the presence of $\mathrm{Na}_{2} \mathrm{HPO}_{4}$ and $\mathrm{NaH}_{2} \mathrm{PO}_{4},{ }^{31,32}$ which suggested that the disproportionation of phosphate might occur in the conversion process.

The comprehensive results of XPS and XRD illustrated that the chemical components of the fluoride-phosphate conversion coating were $\mathrm{Na}_{3} \mathrm{TiF}_{6}, \mathrm{Na}_{3} \mathrm{TiOF}_{5}$, a little $\mathrm{TiO}_{2}, \mathrm{TiF}_{4}$ and phosphate derivatives.

\subsection{Discussion of the formation mechanism}

The $E-t$ curve (Fig. 1), surface morphologies (Fig. 2a-e) and cross-sectional morphology (Fig. 2f) of the conversion coating sufficiently showed that the growth process of the conversion coating was divided into four stages: substrate dissolving ( $0-45$ $\mathrm{s})$; initial nucleation (45-120 s); coating growth (120-600 s, 

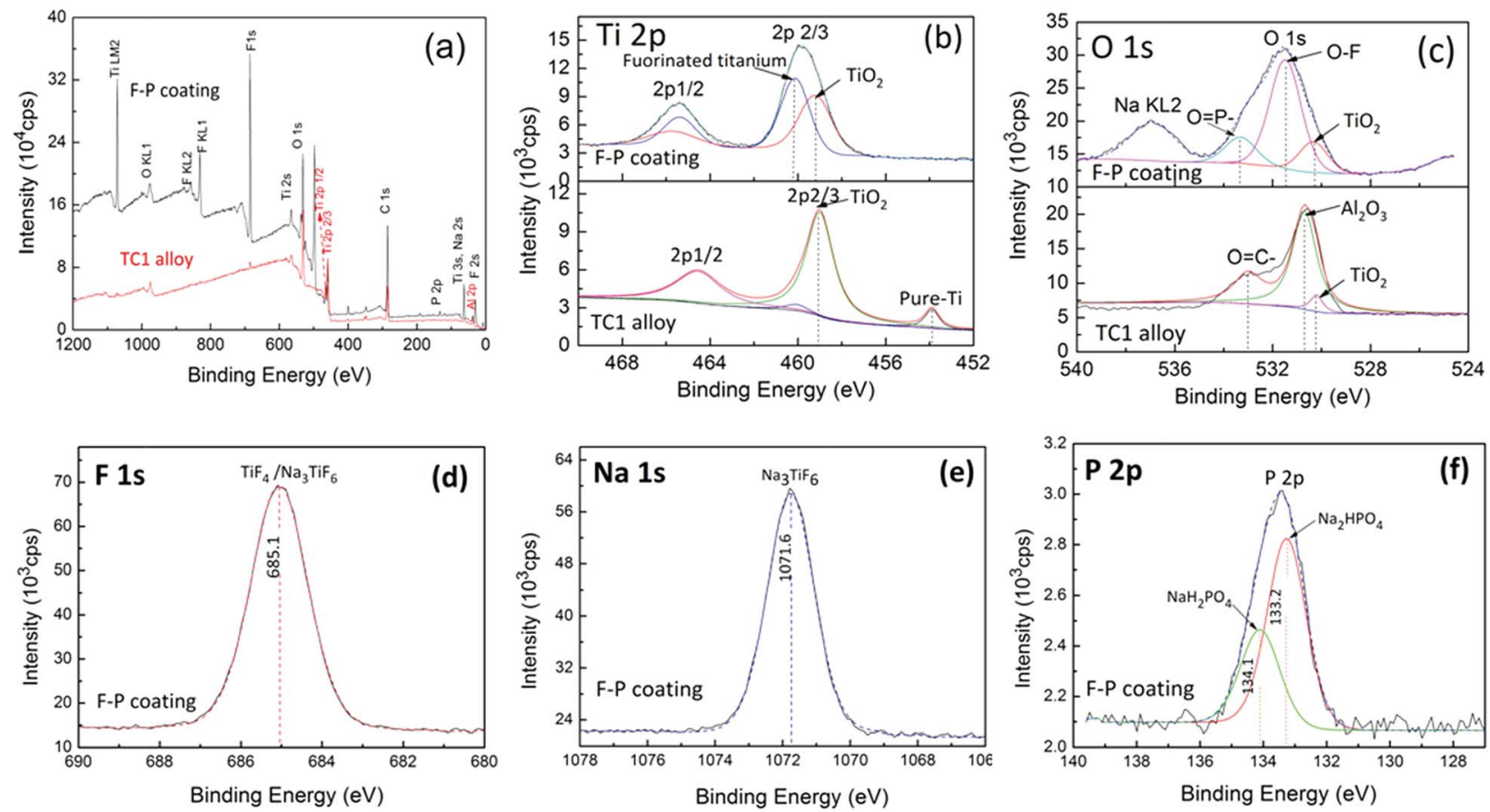

Fig. 4 XPS spectra (a), Ti 2p (b), O 1s (c), F 1s (c), Na 1s (d) and P 2p (e) and XRD spectrum (f) of bare TC1 alloy and the fluoride-phosphate conversion coating formed at $10 \mathrm{~min}$.

including rapid and slow growth) and the dynamic equilibrium of coating growth/dissolution (>600 s). The EDS (Table 1), XRD (Fig. 3) and XPS (Fig. 4) analysis results revealed that the composition of the conversion coating was $\mathrm{Na}_{3} \mathrm{TiF}_{6}, \mathrm{Na}_{3} \mathrm{TiOF}_{5}$, a few $\mathrm{TiO}_{2}, \mathrm{TiF}_{4}$ and phosphate derivatives. Based on previously discussed results, a deposition mechanism of the fluoridephosphate conversion coating is proposed, and is schematically presented in Fig. 5.

The formation of the conversion coating was an electrochemically driven process. ${ }^{\mathbf{2 0}, 21,23}$ The titanium oxide and micro-
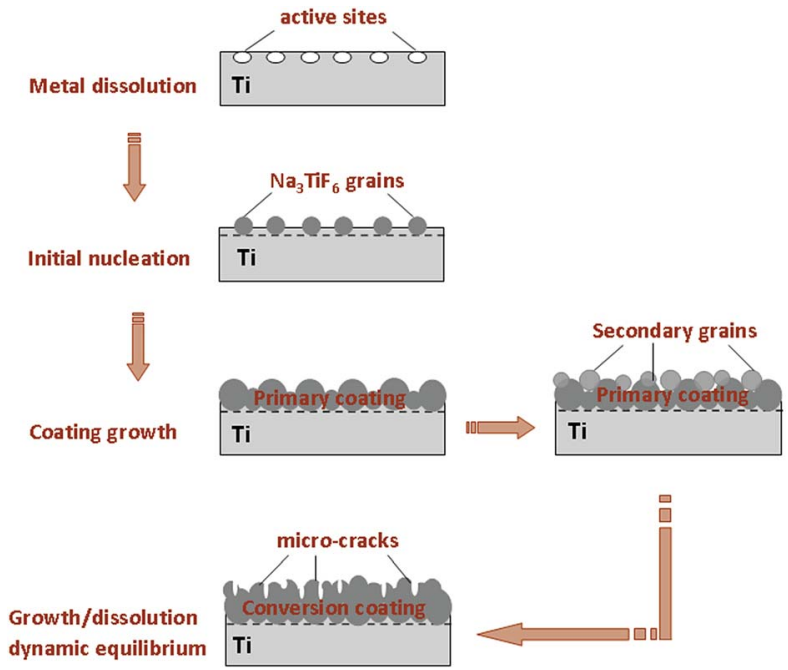

Fig. 5 Deposition model of the fluoride-phosphate conversion coating on titanium alloy. anodes on the titanium surface were successively dissolved to $\mathrm{Ti}^{4+}$ (eqn (1) and (2)) when the titanium sample was immersed in the fluoride-phosphate conversion bath with a $\mathrm{pH}$ of 4.05.0. ${ }^{17}$ Meanwhile, the hydrogen evolution reaction occurred on the micro-cathode sites (eqn (3)). In this stage (0-45 s), the OCP decreased sharply, accompanied with the evolution of hydrogen. Simultaneously, $\mathrm{Na}_{3} \mathrm{PO}_{4}$ and $\mathrm{NaF}$ in the conversion bath were ionized, as shown in eqn (4) and (5). Besides, some $\mathrm{Na}_{3} \mathrm{PO}_{4}$ might be derivatized to $\mathrm{Na}_{2} \mathrm{HPO}_{4}$ and $\mathrm{NaH}_{2} \mathrm{PO}_{4}$ (eqn (6) and (7)) given the presence of $\mathrm{H}^{+} .{ }^{9,32}$

$$
\begin{gathered}
\mathrm{TiO}_{2}+4 \mathrm{H}^{+} \rightarrow \mathrm{Ti}^{4+}+2 \mathrm{H}_{2} \mathrm{O} \\
\mathrm{Ti}-4 \mathrm{e} \rightarrow \mathrm{Ti}^{4+} \\
2 \mathrm{H}^{+}+2 \mathrm{e} \rightarrow \mathrm{H}_{2} \uparrow \\
\mathrm{Na}_{3} \mathrm{PO}_{4} \leftrightarrow 3 \mathrm{Na}^{+}+\mathrm{PO}_{4}^{3-} \\
\mathrm{NaF} \leftrightarrow \mathrm{Na}^{+}+\mathrm{F}^{-} \\
2 \mathrm{Na}^{+}+\mathrm{PO}_{4}^{3-}+\mathrm{H}^{+} \rightarrow \mathrm{Na}_{2} \mathrm{HPO}_{4} \\
\mathrm{Na}^{+}+\mathrm{PO}_{4}{ }^{3-}+2 \mathrm{H}^{+} \rightarrow \mathrm{NaH}_{2} \mathrm{PO}_{4}
\end{gathered}
$$

With the increase of $\mathrm{Ti}^{4+}$ on the electrode/solution interface, $\mathrm{TiF}_{4}$ might be formed when $\mathrm{Ti}^{4+}$ and $\mathrm{F}^{-}$achieve the solubility product (eqn (8)); ; ${ }^{1733}$ meanwhile, a few $\mathrm{Ti}^{4+}$ react with the oxygen in the bath and form a few $\mathrm{TiO}_{2}$ (eqn (9)). Afterwards, $\mathrm{TiF}_{4}$ might react with $\mathrm{NaF}$ step by step to form $\mathrm{Na}_{2} \mathrm{TiF}_{6}$ and $\mathrm{Na}_{3} \mathrm{TiF}_{6}$ nuclei (eqn (10) and (11)) at 45-120 s. ${ }^{26,34}$ As shown in 
Fig. 2a, the grains are formed on the partial sites of the substrate surface by 2 min.

$$
\begin{gathered}
\mathrm{Ti}^{4+}+4 \mathrm{~F}^{-} \rightarrow \mathrm{TiF}_{4} \\
\mathrm{Ti}^{4+}+\mathrm{O}_{2}+4 \mathrm{e} \rightarrow \mathrm{TiO}_{2} \\
\mathrm{TiF}_{4}+2 \mathrm{NaF} \rightarrow \mathrm{Na}_{2} \mathrm{TiF}_{6} \downarrow \\
3 \mathrm{Na}_{2} \mathrm{TiF}_{6}+\mathrm{Ti}+6 \mathrm{NaF} \rightarrow 4 \mathrm{Na}_{3} \mathrm{TiF}_{6} \downarrow
\end{gathered}
$$

With the extension of the conversion time, the $\mathrm{Na}_{3} \mathrm{TiF}_{6}$ grains gradually grow into larger sizes. At the same time, new nuclei are formed on the active sites of the titanium substrate. At 4 min, many large grains appear on the substrate surface (Fig. 2b). The nucleation and growth of $\mathrm{Na}_{3} \mathrm{TiF}_{6}$ grains happens continuously in this stage $(120-600 \mathrm{~s})$. When $\mathrm{Na}_{3} \mathrm{TiF}_{6}$ grains contact with each other (about $6 \mathrm{~min}$ ), a complete conversion coating could be formed on the substrate surface, as shown in Fig. 2c. Thus, the OCP is increased greatly and the coating grows rapidly at $120-420 \mathrm{~s}$.

As the reaction is carried out, the contact area between the substrate and conversion bath is reduced, and the supply rate of $\mathrm{Ti}^{4+}$ for the nucleation decreases, so the growth of the coating slows down. However, secondary grains could be formed on the primary conversion coating, via the stepwise reactions of conversion bath with $\mathrm{Ti}^{4+}$ from the micro-dissolution of the coating. So the conversion coating could still grow slowly in this stage (420-600 s), and the OCP is increased slightly. As shown in Fig. $2 \mathrm{~d}$, the secondary grains and the sub-layer appear on the surface of the complete inner coating.

After $600 \mathrm{~s}$, the dissolving effect of the conversion bath on the coating may dominate the conversion process, and so the coating is in the dynamic stage of growth/dissolution. In this stage, the coating does not grow substantially, and the OCP tends to be stable.

After the conversion treatment, the samples are rinsed thoroughly with deionised water and dried at $100 \pm 5{ }^{\circ} \mathrm{C}$ for 30 min. In this process, some $\mathrm{Na}_{3} \mathrm{TiF}_{6}$ grains react with $\mathrm{O}_{2}$ to form $\mathrm{Na}_{3} \mathrm{TiOF}_{5}$ (eqn (12)), ${ }^{26}$ as demonstrated in Fig. 3 and $4 \mathrm{~d}$ and e.

$$
2 \mathrm{Na}_{3} \mathrm{TiF}_{6}+\mathrm{O}_{2} \rightarrow 2 \mathrm{Na}_{3} \mathrm{TiOF}_{5}+\mathrm{F}_{2}
$$

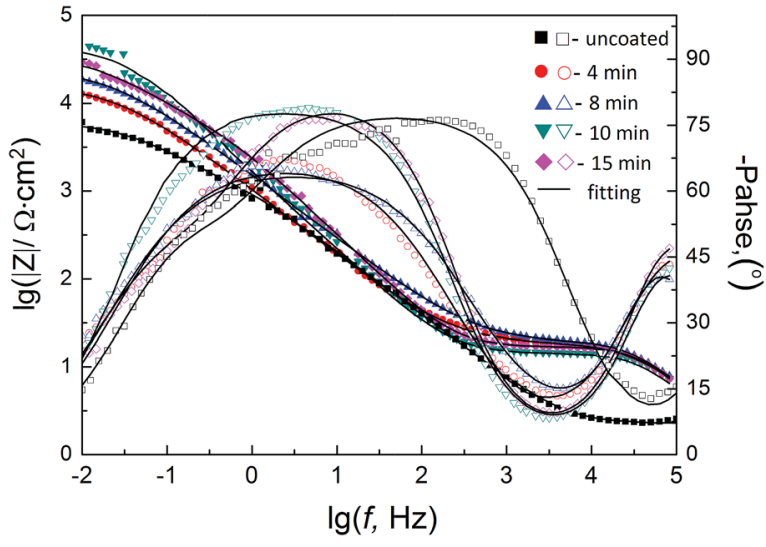

Fig. 6 Bode plots of the fluoride-phosphate conversion coating formed at various times.

\subsection{Corrosion resistance analysis}

EIS has been shown to be an effective method to evaluate the corrosion resistance of conversion coatings. ${ }^{17,20,35,36}$ Fig. 6 shows Bode plots of the fluoride-phosphate conversion coating formed at different times. As shown in Fig. 6, although the bare titanium sample was not treated, the impedance spectroscopy for the uncoated sample still exhibited two time constants at medium and high frequencies. For the metal with a protective layer, the capacitive loop appearing at high frequencies is due to the charge-transfer process, while the capacitive loop at medium frequency is related to the barrier properties of the coating. ${ }^{36,37}$ It could be confirmed that the bare titanium sample covered a partially protective natural passive film, which resulted in the presence of medium-frequency resistance. However, the thin natural passive film could not effectively prevent the invasion of corrosive media, so the uncoated sample had an obscure time constant and a lower charge-transfer resistance at high frequencies.

Instead of a natural passive film, the fluoride-phosphateconversion-coated samples were covered with a compact and protective barrier layer. The conversion coating could effectively avoid the contact between the corrosive media and the titanium substrate. Therefore, the impedance spectroscopy of the fluoride-phosphate-conversion-coated samples clearly appeared two time constants. Besides, the coated samples had a higher impedance value, especially the high-frequency impedance

Table 2 EIS fitting parameter values of the fluoride-phosphate conversion coatings

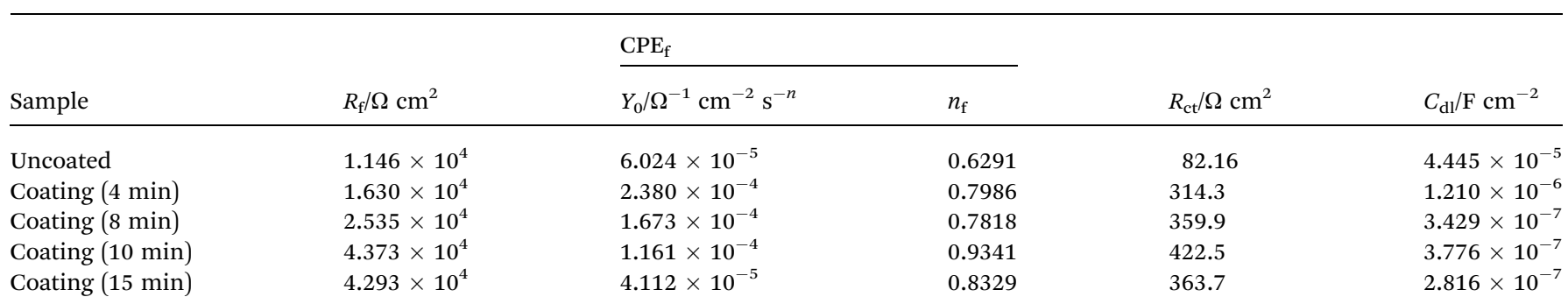




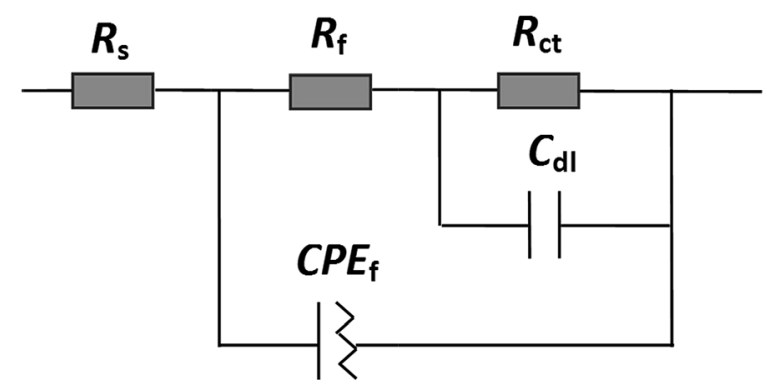

Fig. 7 Equivalent circuit model of the fluoride-phosphate conversion coating formed on titanium alloy.

value compared to the bare sample. Whereas, the low-frequency impedance values of various coatings varied significantly with the conversion time, which indicated that the coverage and barrier property of the conversion coating changed with the conversion time.

According to the physical structure of the electrode, the electrical equivalent circuit shown in Fig. 7 was used to fit the EIS data of the conversion coating. In the circuit, $R_{\mathrm{S}}$ is the solution resistance, $R_{\mathrm{ct}}$ and $C_{\mathrm{dl}}$ represent the charge-transfer resistance and the double-layer capacity at the coating/ electrolyte interface, respectively, and $R_{\mathrm{f}}$ and $\mathrm{CPE}_{\mathrm{f}}$ reflect the coating resistance and the constant phase element delegated coating capacity of the conversion coatings. As shown in Fig. 6, the equivalent circuits provided an excellent fit to the experimental data over most of the frequencies.

Table 2 shows the fitting component values for the EIS. Generally, $R_{\text {ct }}$ could reflect the resistance of the corrosion reactions, while $R_{\mathrm{f}}$ and $n_{\mathrm{f}}$ could illustrate the protection effect and integrity of the conversion coating, respectively. ${ }^{36-38}$ As shown in Table 2, the uncoated titanium sample also had a certain film resistance $\left(R_{\mathrm{f}}\right)$ due to the presence of the natural passive film. But this natural passive film only offered partial protection, which resulted in a low charge-transfer resistance $\left(R_{\mathrm{ct}}\right)$. Compared to the bare sample, the fluoride-phosphateconversion-coated samples had bigger $R_{\mathrm{f}}, n_{\mathrm{f}}$ and $R_{\mathrm{ct}}$ values, which indicated better corrosion resistance. Besides, $R_{\mathrm{f}}, n_{\mathrm{f}}$ and $R_{\mathrm{ct}}$ first increased but then decreased slightly with the increase in conversion time. The conversion coating formed at $10 \mathrm{~min}$ had the biggest $R_{\mathrm{ct}}, R_{\mathrm{f}}$ and $n_{\mathrm{f}}$, and so the conversion coating had higher integrity, bigger resistance and good corrosion resistance. The reasonable explanation for this was that as the grains increased and grew, the integrity of the coating $\left(n_{\mathrm{f}}\right)$ increased with the increasing conversion time. A complete conversion coating had been formed at $6 \mathrm{~min}$, moreover, both a complete inner layer and the secondary grains appeared on the surface at $10 \mathrm{~min}$. Thus, the corrosion resistance of the coating increased within $10 \mathrm{~min}$. However, after $10 \mathrm{~min}$, the micro-dissolution effect of the conversion bath on the coating made the coating became rough, resulting in a decrease in the corrosion resistance of the coating.

\subsection{Paint adhesion}

Fig. 8a and d give the digital photos of the bare and fluoridephosphate coated TC1 samples. It can be seen that a uniform and smooth grey conversion coating (Fig. 8d) was formed when the titanium sample was treated in a fluoride-phosphate bath
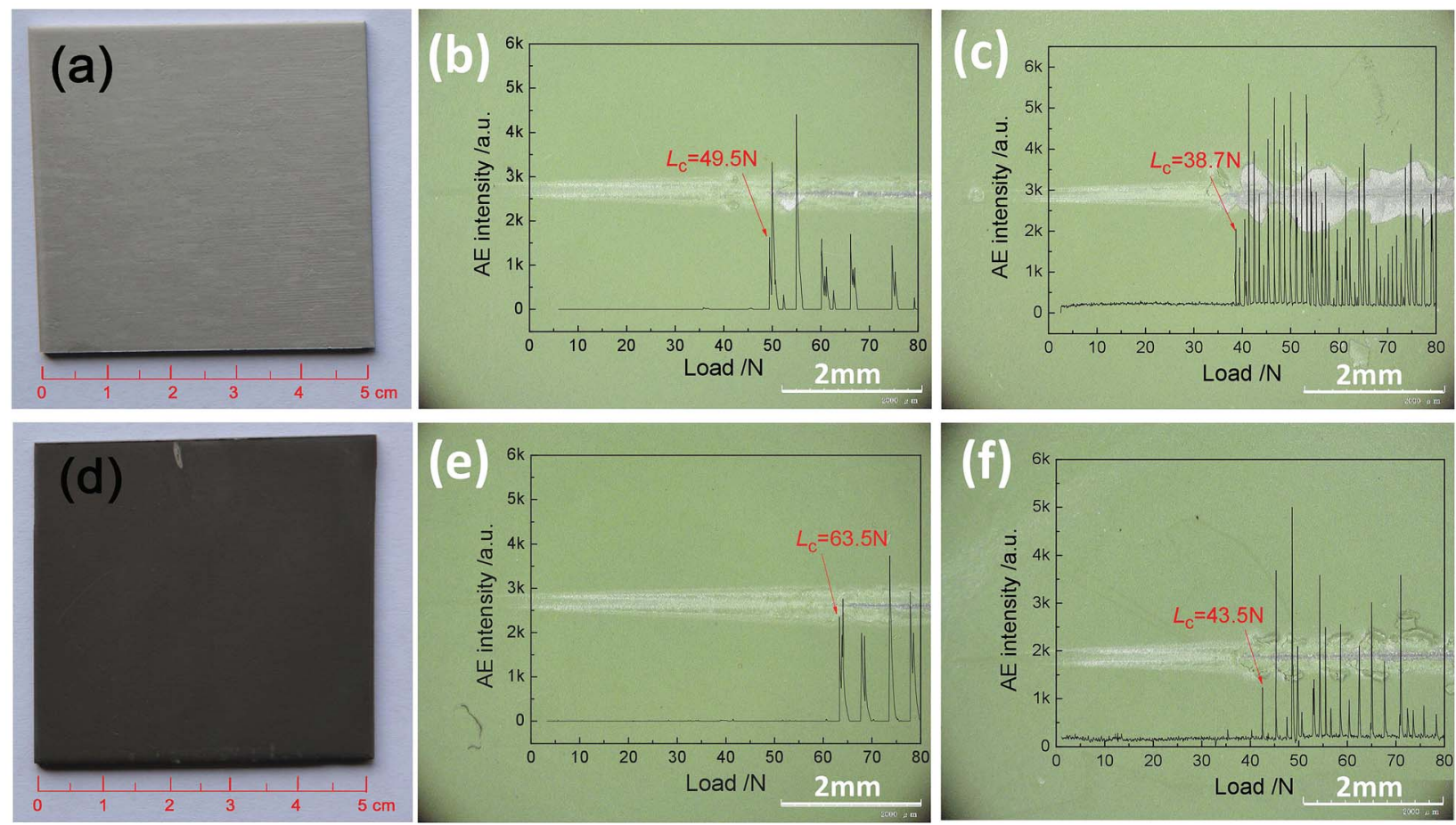

Fig. 8 OM image $(a, d)$, dry paint-adhesion (b, e) and wet paint-adhesion (c, f) of the TC1 alloy (a-c) and the fluoride-phosphate conversion treated alloy $(d-f)$. 
for $10 \mathrm{~min}$. This colouring effect enabled the researchers to visually monitor the coating development and to assess the quality of the resulting coating.

Besides, the polyurethane coating was applied on the surface of the bare sample and the fluoride-phosphate coated sample. The dry and wet adhesion strength values of the paint coat to the substrates were measured by scratch testing. The scratchinduced surface photographs and $\mathrm{AE}$ signal curves of the various samples are shown in Fig. 8b, c, e and f. The critical load $\left(L_{\mathrm{C}}\right)$ that the coating peeled off was confirmed by the scratch tracks and AE signals. ${ }^{5,25,38}$

As shown in Fig. 8b and e, the dry adhesion values $\left(L_{\mathrm{C}}\right)$ of the polyurethane coating to the bare and fluoride-phosphatecoated sample were $49.5( \pm 2.2) \mathrm{N}$ and $63.5( \pm 1.8) \mathrm{N}$, respectively. When the paint-coated samples were exposed to $\mathrm{NaCl}$ solution for 7 days, the wet-paint-adhesion strength of the polyurethane coating to the substrates significantly decreased, but the $L_{\mathrm{C}}(43.5 \pm 0.8)$ of the fluoride-phosphate treated sample was still higher than the $L_{\mathrm{C}}(38.7 \pm 0.3)$ of the untreated sample. The results are presented in Fig. 8 and show that the fluoridephosphate conversion treatment resulted in an improvement in the polyurethane coating adhesion properties, especially the wet paint-adhesion. Many researchers have suggested that conversion coatings increased the paint-adhesion strength through increasing the wet ability and surface roughness. ${ }^{39,40}$ In this way, the fluoride-phosphate conversion coating with a granular cell structure, consisting of $\mathrm{Na}_{3} \mathrm{TiF}_{6}, \mathrm{Na}_{3} \mathrm{TiOF}_{5}, \mathrm{TiO}_{2}$ and $\mathrm{TiF}_{4}$, could create the stronger physical/chemical bonds between the paint and substrate, which might be a reasonable explanation for the increase in paint adhesion.

\section{Conclusions}

(1) A uniform, coherent and grey conversion coating with a thickness of 4-5 $\mu \mathrm{m}$ was prepared when TC1 titanium alloy was immersed in a fluoride-phosphate bath.

(2) The growth process for the conversion coating was divided into four stages: substrate dissolving $(<45 \mathrm{~s})$; initial nucleation (45-120 s); coating growth (120-600 s) and dynamic equilibrium of the coating growth/dissolution (>600 s). $\mathrm{Na}_{3} \mathrm{TiF}_{6}$ nucleation occurred initially, and then increased and grew continuously to form the conversion coating. Some $\mathrm{Na}_{3} \mathrm{TiF}_{6}$ grains reacted with $\mathrm{O}_{2}$ to form $\mathrm{Na}_{3} \mathrm{TiOF}_{5}$ in the drying process at $100 \pm 5{ }^{\circ} \mathrm{C}$. The main composition of the conversion coating was $\mathrm{Na}_{3} \mathrm{TiF}_{6}, \mathrm{Na}_{3} \mathrm{TiOF}_{5}$, a little $\mathrm{TiO}_{2}, \mathrm{TiF}_{4}$ and phosphate derivatives.

(3) Fluoride-phosphate conversion coating improved the corrosion resistance of titanium alloy. The conversion coating formed at $10 \mathrm{~min}$ had better corrosion resistance than the others.

(4) Fluoride-phosphate conversion coating greatly enhanced the adhesion between the titanium alloy and organic coating.

\section{Acknowledgements}

The authors gratefully acknowledge the financial support of Open Foundation of National Defense Key Discipline
Laboratory of Light Alloy Processing Science and Technology, Nanchang Hangkong University (Grant No. gf201501002).

\section{References}

1 R. R. Boyer, Mater. Sci. Eng., A, 1996, 213, 103-114.

2 M. Peters, J. Kumpfert, C. H. Ward and C. Leyens, Adv. Eng. Mater., 2003, 5, 419-427.

3 W. Kaysser, Surf. Eng., 2001, 17, 305-312.

4 X. L. Liu, P. K. Chu and C. X. Ding, Mater. Sci. Eng., R, 2004, 47, 49-121.

5 B. Liu, G. Y. Xiao, C. C. Jiang, Y. Z. Zheng, L. L. Wang and Y. P. Lu, RSC Adv., 2016, 6, 75365-75375.

6 F. W. Eppensteiner and M. R. Jenkins, Met. Finish., 2000, 98, 497-509.

7 P. Campesrini, G. Goeminne and H. Terryn, J. Electrochem. Soc., 2004, 151, B59-B70.

8 T. S. N. S. Sanakara, Rev. Adv. Mater. Sci., 2005, 9, 130-177. 9 X. C. Zhao, G. Y. Xiao, X. Zhang, C. C. Jiang, H. Y. Wang and Y. P. Lu, Rare Met. Mater. Eng., 2014, 43, 306-309.

10 P. Bhatia, Met. Finish., 2004, 102, 92.

11 H. Neuder and C.-T. Liu, J. Coat. Technol., 2002, 74, 37-42.

12 AMS 2486D, Conversion Coating of Titanium Alloys: FluoridePhosphate Type, 2004.

13 B. Valdez, S. Kiyota, M. Stoytcheva, R. Zlatev and J. M. Bastidas, Corros. Sci., 2014, 87, 141-149.

14 E. M. Palomino Luis, V. Aoki Idalina and G. de Melo Hercílio, Electrochim. Acta, 2006, 51, 5943-5953.

15 C.-S. Liang, Z.-F. Lv, Y.-L. Zhu, S.-A. Xu and H. Wang, Appl. Surf. Sci., 2014, 288, 497-502.

16 M. G. S. Ferreira, R. G. Duarte, M. F. Montemor and A. M. P. Simões, Electrochim. Acta, 2004, 49, 2927-2935.

17 L. Li, J. He and X. Yang, Appl. Surf. Sci., 2016, 371, 488-493. 18 T. Chen, W. Li and J. Cai, RSC Adv., 2001, 1, 607-610.

19 L. Li, W. W. Brandon and M. Swaina Greg, J. Electrochem. Soc., 2015, 162, C279-C284.

20 T. Lostak, A. Maljusch, B. Klink, S. Krebs, M. Kimpel, J. Flock, S. Schulz and W. Schuhmann, Electrochim. Acta, 2014, 137, 65-74.

21 A. Yi, W. Li, J. Du and S. Mu, Surf. Interface Anal., 2015, 47, 863-870.

22 D. Susac, X. Sun, R. Y. Li, K. C. Wong, P. C. Wong, K. A. R. Mitchell and R. Champaneria, Appl. Surf. Sci., 2004, 239, 45-49.

23 J. H. Nordlien, J. C. Walmsley, H. Østerberg and K. Nisancioglu, Surf. Coat. Technol., 2002, 153, 72-78.

24 F. O. George, P. Skeldon and G. E. Thompson, Corros. Sci., 2012, 65, 231-237.

25 X. L. Cai, Y. H. Xu, N. Zhao, L. S. Zhong, Z. Y. Zhao and J. Wang, Surf. Coat. Technol., 2016, 299, 135-142.

26 K. Borowiec, A. Przepiera and K. Kolbrecka, J. Therm. Anal., 1991, 37, 637-644.

27 A. H. Yi, W. F. Li, J. Du and S. L. Mu, Appl. Surf. Sci., 2012, 258, 5960-5964.

28 G. L. Georgiev, T. Sultana, R. J. Baird, G. Auner, G. Newaz, R. Patwa and H. Herfurth, Appl. Surf. Sci., 2008, 254, 71737177. 
29 T. Sultana, G. L. Georgiev, G. Auner, G. Newaz, H. J. Herfurth and R. Patwa, Appl. Surf. Sci., 2008, 255, 2569-2573.

30 F. Fracassi and R. d'Agostino, Pure Appl. Chem., 1992, 64, 703-707.

31 P.-H. Lo, W.-T. Tsai, J.-T. Lee and M.-P. Hung, J. Electrochem. Soc., 1995, 142, 91-96.

32 F. Li and G. Wang, J. Mater. Eng. Perform., 2016, 25, 18641869.

33 M. Stancheva and M. Bojinov, Electrochim. Acta, 2012, 78, 6574.

34 H.-H. Huang, Biomaterials, 2003, 24, 275-282.
35 M. E. Orazem and B. Tribollet, Electrochemical Impedance Spectroscopy, Wiley, John \& Sons, Incorporated, 1st edn, 2008.

36 S. H. Zhang, G. Kong, J. T. Lu, C. S. Che and L. Y. Liu, Surf. Coat. Technol., 2014, 259, 654-659.

37 S. Y. Jian, Y. R. Chu and C. S. Lin, Corros. Sci., 2015, 93, 301309.

38 X. Boddaert, G. Covarel, B. Bensaid, M. Mattei, P. Benaben and J. Bois, Thin Solid Films, 2013, 528, 194-198.

39 T.-W. Seo and J. Weon, J. Mater. Sci., 2012, 47, 2234-2240.

40 H. Vakili, B. Ramezanzadeh and R. Amini, Corros. Sci., 2015, 94, 466-475. 